RELACult - Revista Latino-Americana de Estudos em Cultura e Sociedade e-ISSN 2016/Atual: 2525-7870 | e-ISSN 2015/2016: 2447-018X

\title{
A Difusão Das Notícias Ambientais Na \\ Contemporaneidade: Uma Reflexão Sobre O Conhecimento \\ Científico em Processos Decoloniais
}

A Difusión De Noticias Del Medio Ambiente En

Contemporánea: Una Reflexión Sobre El Conocimiento

Los Procesos Científicos En Descolonial

The Dissemination Of Environmental News In

Contemporaneity: A Reflection On The Knowledge

Scientific Processes In Decolonial

Bel. Ariella Dias de Souza ${ }^{1}$

Dra. Betania Maciel ${ }^{2}$

\begin{abstract}
Resumo
O artigo apresenta a reflexão sobre a divulgação dos estudos científicos em processos decoloniais, especificamente os voltados para os estudos ambientais na perspectiva da construção de valores humanos e sustentáveis. O paradigma colonialidade-modernidade decorre ao âmbito contemporâneo em que os processos comunicacionais coexistem a serviço do capitalismo e da sociedade. A pesquisa teve como referencia jornalística o portal de notícias do maior grupo de comunicação de massa do Brasil, o G1 da Rede Globo.
\end{abstract}

Palavras-Chave: divulgação científica; notícias ambientais; processos decoloniais; sustentabilidade.

\section{Resumen}

El artículo presenta una reflexión sobre la difusión de los estudios científicos procesos descoloniales, centrado específicamente en los estudios ambientales en la perspectiva de la construcción de los valores humanos y sostenibles. El paradigma de la colonialidad-moderna se deriva del contexto actual en el que coexisten pro cesos de comunicación al servicio del capitalismo y la sociedad. La investigación fue referencias periodísticas el portal de noticias del mayor grupo de medios de comunicación en Brasil, el G1 de Globo.

Palabras Clave: ciencia popular; noticias ambientales; procesos descoloniales; la sostenibilidad

\section{Abstract}

The article presents a reflection on the dissemination of scientific studies decolonial processes, specifically focused on environmental studies in the perspective of building human and sustainable values. The colonialitymodern paradigm stems from the contemporary context in which communication processes coexist in the service

\footnotetext{
${ }^{1}$ Bacharela em Jornalismo, mestranda em Extensão Rural e Desenvolvimento Local; Universidade Federal Rural de Pernambuco - UFRPE; Recife, Pernambuco, Brasil; ariella_dias@ hotmail.com.

${ }^{2}$ Doutora em Comunicação Social; Universidade Federal Rural de Pernambuco - UFRPE; Recife, Pernambuco, Brasil; betaniamaciel@gmail.com.
} 
of capitalism and society. The research was journalistic references the news portal of the largest mass media group in Brazil, the Gl Globo.

Keywords: science communication; environmental news; decolonial processes; sustainability.

\section{Introdução}

Esta pesquisa teve o objetivo de refletir a divulgação dos estudos científicos ambientais, a partir da análise do portal de notícias G1 pertencente à Rede Globo, maior grupo de comunicação de massa do Brasil. O ensejo recorreu à valorização do comportamento sustentável em que a preservação do meio ambiente é intrínseca aos direitos à qualidade de vida e bens sociais inclusivos, no âmbito contemporâneo decorrente dos processos decoloniais, ou seja, na perspectiva pós-colonial latino-americana.

O estudo monitorou por um mês ${ }^{3}$ as seções Educação, Natureza, Ciência e Saúde, as quais foram consideradas pertinentes para a divulgação de notícias ambientais científicas. $\mathrm{O}$ veículo de comunicação escolhido se deve por disponibilizar o acesso gratuito e por ser virtual, uma vez que vivenciamos o aumento crescente de público da internet com relação aos demais meios, inclusive a televisão.

A reflexão teve como princípio o exercer do papel da mídia para a construção da cultura sustentável, ou seja, o uso colaborativo dos recursos disponíveis para o suporte da instrução ambiental à sociedade, através da visibilidade dos estudos científicos. No entendimento de o comportamento socioambiental permear em todas as esferas em incentivo à participação cidadã, sem restrição de espaços e com a consideração das questões sociais, econômicas e culturais, ou seja, motivando a melhoria da qualidade de vida humana e do meio ambiente. Assim como Bourdieu (1997) propôs a Realpolitik, que consiste em qualquer pessoa independente de sua posição social poder exercer o papel político na sociedade em benefícios coletivos:

\footnotetext{
"O princípio de toda Realpolitik da razão, que eu prego, consiste em acumular o máximo possível de autoridade específica para fazer uso dela, se for o caso, uma força política sem, é claro, para isso torna-se um homem político.” (BOURDIEU, 1997, p. 74).
}

Neste contexto, o entendimento do poder para o uso da palavra consiste na formação da opinião pública, em que o emissor além de informar, também pode contribuir para o despertar da consciência ambiental através da divulgação dos estudos científicos.

\footnotetext{
${ }^{3} \mathrm{O}$ monitoramento ocorreu de 14 de setembro e 14 de outubro de 2015.
} 

e-ISSN 2016/Atual: 2525-7870 | e-ISSN 2015/2016: 2447-018X

Incentivando, assim, a responsabilidade coletiva e individual para o desenvolvimento das potencialidades endógenas, voltadas para a inclusão social e às demandas sustentáveis.

\section{Processos Decoloniais}

Da mesma maneira como Chaui (2000, p. 28) elucidou sobre a importação de ideias estrangeiras no Brasil no período colonial, devido à falta de amadurecimento da classe operária e a difícil definição sociológica da classe média para a formação ideológica, as influencias dos processos decoloniais na mídia foram norteadas pelos modelos hegemônicos. Na era da comunicação digital, o que notamos é o caráter nacional reproduzindo os padrões estabelecidos pelos países considerados desenvolvidos, uma vez que então somos chamados de emergentes, ainda em processo de avanço. São os mesmos princípios adotados em um passado remoto, conforme refletiu Chaui, mantidos pela nação neoliberal que acredita caminhar para o progresso engajada na globalização massificada.

O portal G1 é o exemplo deste fundamento austero, a pesquisa constatou o compartilhamento de notícias, inclusive na íntegra, do portal de noticias BBC Brasil pertencente ao grupo internacional BBC, além do mesmo estilo de layout e cores adotados. $\mathrm{O}$ que aumenta a reflexão é a complexidade da situação mercadológica que envolve os profissionais da comunicação e torna homogênea a postura das redações jornalísticas. Segundo os estudos de Comby (2005), na França, sobre o papel da imprensa na conscientização ambiental, os jornalistas são equiparados aos "escravos intelectualizados" devido ao excesso de funções, a pouca remuneração com relação ao trabalho exercido e a submissão ao mercado excludente.

No Brasil não há diferença, cada vez mais as editorias segmentadas assumem as atividades polivalentes para o aumento de produção e a diminuição de contratações profissionais. No portal G1, percebemos que apesar de a Rede Globo possuir editorias jornalísticas em cada Estado brasileiro, inclusive com subeditorias por regiões, não produz conteúdo informativo local com planejamento periódico. As páginas Educação, Natureza e Ciência e Saúde são as mesmas em todo o país, com as notícias compartilhadas entre os canais locais, regionais e nacional.

Só em Pernambuco são sete endereços virtuais diferentes que direcionam para o mesmo conteúdo. É a tecnologia voltada para a velocidade da informação, guiada pelo estruturalismo reducionista legitimado pela lógica do desenvolvimento hegemônico. Os processos decoloniais nos meios de comunicação mantém a solidez dos comportamentos historicamente estabelecidos pelas reproduções iniciadas no período colonial. 
O ritmo mecanicista atroz despreza aprofundamentos nos conteúdos jornalísticos e o comprometimento com a qualidade do que está sendo noticiado. Os estudos voltados para a Ciência e Tecnologia (C\&T) têm discutido o campo fértil para as fáceis interpretações, em detrimento da elevação da consciência e das responsabilidades sociais. Colombo e Bazzo (2001) elucidaram à Organización dos Estados Iberoamericanos sobre os avanços tecnológicos separados das questões inerentes à qualidade de vida.

(...) Muitas vezes concebemos a nós mesmos como complexas máquinas físicoquímicas com um cérebro, que pode ser comparado a um potente e complicado computador. Porém devemos estar alerta quanto a reduzirmo-nos a um simples objeto da técnica, ou vincular a realização de nossos sonhos e a resposta a nossas angústias aos avanços tecnológicos. (COLOMBO; BAZZO, 2001, p. 1).

Assim, os ciberespaços conectados pela telemática são aproximados a um click enquanto sofrem as consequências do distanciamento das sociabilidades, sensíveis à atuação cidadã. Noticiam os desastres ambientais provenientes do aquecimento global, mas não os relacionam com as responsabilidades individuais. A população é informada sobre a descoberta de água em marte, mas não recebe notícia sobre os estudos científicos de sua região. Em Pernambuco, universidades federais desenvolvem projetos com unidades instaladas em locais distantes do eixo metropolitano, mas as notícias do G1 Caruaru, Petrolina e Região são as mesmas que os recifenses, paulistas, paraenses e rio-grandenses, dentre outros, acessam.

\section{Ciência \& Sociedade Brasileira}

Conforme estudos desenvolvidos na Primeira Oficina de Indicadores de Percepção Pública, Cultura Científica e Participação Cidadã, por iniciativa da Rede Iberro-Americana de Indicadores de Ciência e Tecnologia, o Brasil foi o único país dentre os participantes que reconheceu a racionalidade da ciência de forma legítima com 70,4\% dos entrevistados. Bem à frente da Argentina, Espanha e Uruguai, com 27,2\%.

Os dados, que revelaram a adesão da maioria dos brasileiros às informações científicas, demonstraram a ambiência favorável para a apropriação das orientações cientificas, sendo os meios de comunicação de massa importantes instrumentos no processo informativo à sociedade. Contudo, apesar de realizada a divulgação de estudos científicos, o que se percebe é a pouca importância que o modelo fordista faculta às informações que estão sendo propagadas. Como se o que estivesse sendo divulgado não influenciasse na vida da 
própria pessoa que está redigindo o texto assim como Colombo e Bazzo falaram sobre a robotização das pessoas.

\section{Perfil das Seções Analisadas}

\subsection{Educação}

A página Educação apresentou ênfase aos assuntos direcionados aos estudantes de pré-vestibular. A editoria não mantém atenção às questões ambientais. A abordagem do meio ambiente ficou reservada para a seção Natureza. Foi percebido que a Educação é considerada como uma categoria independente dos assuntos ambientais, como se não houvesse relação entre ambos os assuntos.

No entendimento de o termo educação designar os processos de construção do conhecimento, percebemos que a seção Educação não se volta para este conceito e sim para o conteúdo relativo ao vestibular e mercado de trabalho, com público bem definido neste contexto.

\subsection{Ciência E Saúde}

Apesar do título, a página apresenta de forma predominante o conteúdo voltado para os estudos astronômicos, postura comum ocorrida em outros veículos de comunicação, como se os estudos científicos fossem especificamente relativos à astronomia. As poucas notícias publicadas de acordo com a proposta desta pesquisa estavam simultâneas na Natureza.

\subsection{Natureza}

Por se tratar de uma página segmentada de acordo com o tema desta pesquisa, conforme o próprio título da seção informa, não foram consideradas no monitoramento as notícias sem relação com o meio ambiente de forma que problematizasse a questão tratada, ou seja, o estudo com morcegos voltados para a insônia humana, apesar de ter relação com a natureza, não está dentro os parâmetros do objeto desta pesquisa. Assim, o monitoramento considerou assunto como: recorde de queimadas com o número de incêndios acima de 11 mil no Amazonas; desertificação avançando em Alagoas; furacão que atingiu Bahamas e EUA; riscos de hidrelétrica e ameaças às espécies; falhas em estudo da ONU sobre o impacto ambiental; tempestade que virou furacão no México; incêndios florestais em Brasília; falsificação de resultados de emissões de poluentes de empresa multinacional; e a queda de animais marinhos pela metade, dentre outras. 

e-ISSN 2016/Atual: 2525-7870 | e-ISSN 2015/2016: 2447-018X

Na seção foram observadas duas colunas de opinião, a Mundo Sustentável por André Trigueiro, sem atualização periódica. E a Nova Ética Social por Amelia Gonzalez, esta com mais inserções. Importante ressaltar que a jornalista Amelia surpreendeu ao apresentar textos reflexivos trazendo à tona assuntos poucos questionados pela mídia.

\section{Resultado}

Para a reflexão sobre a visibilidade do comportamento sustentável na mídia, a pesquisa considerou no monitoramento as seguintes categorias: (1) Estudos Científicos Ambientais e (2) Notícias Ambientais. Sendo a primeira, analisada em duas subcategorias: (1.1) Estudos Científicos Ambientais Acadêmicos e (1.2) Estudos Científicos Ambientais Institucionais (que seriam os não acadêmicos, relativos às instituições diversas, como ONGs, órgãos privados ou governamentais, etc), para que assim também pudéssemos compreender a atenção deferida à academia científica. No contexto de a mídia poder encurtar a distância entre a ciência e a sociedade civil.

O estudo, ocorrido de forma diária, também observou as chamadas em destaques na página principal (home) do portal, no entendimento da possibilidade de facilitação para o acesso às informações, pois o público não segmentado poderia ser alcançado sem que houvesse o interesse pela busca, conforme reza a Lei Federal 9.795, artigo $3 \%$ IV, que estabelece o dever dos meios de comunicação de massa em "colaborar de maneira ativa e permanente na disseminação de informações e práticas educativas sobre meio ambiente e incorporar a dimensão ambiental em sua programação".

Apenas uma notícia mereceu destaque na página principal, mas por estar relacionada ao discurso da presidente Dilma Rousseff com relação à conferência internacional do clima ocorrida em Paris e não exatamente à preocupação com as questões ambientais, uma vez que o assunto foi considerado pertinente pela mídia devido ao momento do evento e não de fato por interesse do próprio corpo técnico jornalístico ao tema.

Dessa maneira, apesar de a pesquisa ser voltada especificamente para os estudos científicos ambientais, não foram desconsideradas as publicações relativas ao meio ambiente sem o teor científico. Sendo essas configuradas na categoria (2), como Notícias Ambientais. O resultado do monitoramento do portal G1 apresentou na seção Educação apenas uma publicação relacionada ao Estudo Científico Ambiental, sendo essa Acadêmica. E, sem caráter científico, uma Notícia Ambiental.

Na Ciência e Saúde foram constadas 19 publicações relativas aos Estudos Científicos Ambientais, subdividas em 9 Acadêmicas e 10 Institucionais. Na categoria Notícia Ambiental, foram registradas 5 inserções. Por fim, na Natureza obtivemos 33 publicações 

e-ISSN 2016/Atual: 2525-7870 | e-ISSN 2015/2016: 2447-018X

relacionadas aos Estudos Científicos Ambientais: 9 Acadêmicas e 24 Institucionais. Mais 49 Notícias Ambientais.

Tabela 1 - Categorias Analisadas.

\begin{tabular}{|l|c|c|}
\hline \multicolumn{1}{|c|}{ Seções } & Estudos Científicos Ambientais & Notícias Ambientais \\
\hline Educação & 1 & 1 \\
\hline Ciência e Saúde & 19 & 5 \\
\hline Natureza & 33 & 49 \\
\hline
\end{tabular}

Tabela 2 - Subcategorias dos Estudos Científicos Ambientais.

\begin{tabular}{|l|c|c|}
\hline \multicolumn{1}{|c|}{ Seções } & Estudos Científ. Amb. Acadêmicos & Estudos Científ. Amb. Institucionais \\
\hline Educação & 1 & 0 \\
\hline Ciência e Saúde & 9 & 10 \\
\hline Natureza & 9 & 24 \\
\hline
\end{tabular}

A pesquisa considerou o número de publicações gerais sem especificidade aos estudos científicos ambientais, ao dia, para que pudéssemos ter o parâmetro de análise ao objeto de estudo. Assim, a média de inserções diárias em cada seção foram de 3 a 6 notícias, com ocasiões excepcionais de até 16 publicações num único dia. Ao adotarmos o número mínimo de 3 publicações e multiplicarmos por 30, equivalente ao período de análise, teremos o quantitativo geral de pelo menos 90 inserções em cada seção ao mês. Parâmetro considerado mínimo para uma análise menos rígida. $\mathrm{O}$ que nos leva à conclusão que as 33 publicações na seção Natureza representa a visibilidade de $37 \%$ aos Estudos Científicos Ambientais, sucessivamente $22 \%$ na Ciência e Saúde e 1\%, na Educação. Quantitativo que revela a baixa expressividade, principalmente por considerarmos que nenhuma notícia de caráter ambiental teve destaque com chamada na página principal do portal G1, mesmo sendo algumas sérias, como desastres ambientais e o estudo alarmante que revelou o drástico avanço do mar no litoral paulista.

A coluna a Nova Ética Social pode ser considerada o grande achado desta pesquisa, pois praticamente todos os textos abordados trouxeram assuntos polêmicos e enriquecedores com informações além do aporte momentâneo amparado pela agenda midiática. Contudo, permaneceu "reservada" para o público segmentado, ou seja, aquele que procura pela notícia ambiental e entra por iniciativa própria na seção Natureza. O grande público, que navega a 
partir das chamadas em destaque na home, infelizmente correu o grande risco de não ter acesso ao conteúdo.

\section{Conclusão}

Conforme reflete Tauk Santos (2016, p.81), combinar os avanços tecnológicos em sintonia com as novas perspectivas de desenvolvimento é um desafio para a comunicação nas novas formas de ação política. Conforme a autora, a concepção do desenvolvimento na perspectiva do local e sustentável combina ao avanço tecnológico às novas sociabilidades. Assim, é imprescindível a sintonia com as novas formas de se fazer política na perspectiva de a comunicação, como instrumento viabilizador, atuar nos processos de construção mobilizadora para as aspirações sustentáveis.

A construção dos saberes, aspirados por atitudes colaborativas, pode transformar as influencias decoloniais perpetuadas. Para isto, além dos educadores, cabe também aos profissionais portadores de potencialidades para a formação da opinião pública o avanço em seus papéis sociais.

As organizações da Rede Globo são as maiores agentes comunicacionais do Brasil, sendo o seu padrão de gestão considerado como modelos para variados veículos de comunicação e, inclusive, organizações concorrentes. O resultado obtido através da análise do portal G1 é preocupante porque representa a metodologia de um corpo editorial, despreocupado com o seu comprometimento ambiental e social, ditando as formas de reprodução de modelos.

É necessária uma nova dinâmica nas relações para se recriar outras racionalidades, pautadas pela valorização da biodiversidade e conservação ambiental, para além das dimensões ecológicas rumo às sociais, culturais, econômicas e políticas. Neste sentido, a comunicação para o desenvolvimento é instrumento que aponta para a superação dos problemas postos, a partir da incorporação do culturalismo versus o estruturalismo pensado por Gramsci, ou seja, a transformação cultural. Cultura, aqui mencionada no sentido das práticas e modos de vida sociais, constituídos não apenas pelos processos da cultura de massa impostos, mas também pelas reconversões realizadas pelos populares. Em sumo, conforme analisa Escosteguy (2001, p. 107) sobre "interrogar-se sobre as mútuas determinações entre culturas populares e outras formas discursivas", no que está como objeto deste estudo as possibilidades de se articular políticas e ideologias voltadas para as práticas culturais sustentáveis. 


\section{Referências}

BOURDIEU, Pierre. Os Usos Sociais Da Ciência: por uma sociologia clínica do campo cientifico. Tradução Denice Barbara Catani. São Paulo: Editora Unesp, 2004.

BRASIL, Lei Federal 9.795, artigo 3\% IV, que estabelece aos meios de comunicação de massa a colaboração na disseminação de informações e práticas educativas sobre meio ambiente. Disponível em: www.planalto.gov.br/ccivil_03/leis/L9795.htm.

CHAUI, Marilena. Brasil: mito fundador e sociedade autoritária. São Paulo: Editora Fundação Perseu Abramo, 1996.

COLOMBO, Ciliana; BAZZO, Walter. Educação Tecnológica Contextualizada, ferramenta essencial para o desenvolvimento social brasileiro. Biblioteca Virtual da OEI Ciencia, tecnología y sociedad - Enseñanza Técnica, disponível em: http://www.campus-oei.org/oeiv, 2001.

ESCOSTEGUY, A. C. Cartografias dos Estudos Culturais: uma versão latino-americana. Belo Horizonte: Autêntica Editora, 2001.

FREIRE, P. Extensão ou Comunicação?. 10 ed. São Paulo/ Rio de Janeiro: Editora Paz e Terra, 1988.

Minicurso Mídia e Meio Ambiente, 2015, Recife: UFPE. Palestra: A Distinção, 30 Anos Depois. COMBY, Francoise Jean-Baptiste.

TAULK SANTOS, M. S. Comunicação para o Desenvolvimento: redes da memória. Recife: Companhia Editora de Pernambuco - CEPE, 2016. 